\title{
Intake of Korean Red Ginseng Extract and Saponin Enhances the Protection Conferred by Vaccination with Inactivated Influenza A Virus
}

\author{
Mei Ling Xu, Hyoung Jin Kim, Yoo Ri Choi, and Hong-Jin Kim* \\ College of Pharmacy, Chung-Ang University, Seoul 156-756, Korea
}

\begin{abstract}
Vaccination is the main strategy for preventing influenza infection. However, vaccine efficacy is influenced by several factors, including age and health status. The efficacy of the influenza vaccine is much lower (17\% to 53\%) in individuals over 65 yr of age compared with young adults ( $70 \%$ to $90 \%)$. Therefore, increasing vaccine efficacy remains a challenge for the influenza vaccine field. In this study, we investigated the impact of supplementing vaccination with the dietary intake of Korean red ginseng (RG) extract and RG saponin. Mice were immunized two times intranasally with inactivated influenza A (H1N1) virus. Mice received RG extract or RG saponin orally for $14 \mathrm{~d}$ prior to the primary immunization. After the primary immunization, mice continued to receive RG extract or RG saponin until the secondary immunization. Mice vaccinated in combination with dietary intake of RG extract and RG saponin showed elevated serum anti-influenza A virus IgG titers and improved survival rates in lethal influenza A virus infection: $56 \%$ and $63 \%$ of mice receiving RG extract or RG saponin survived, respectively, while $38 \%$ of mice that only received the vaccine survived. Moreover, mice receiving RG extract supplementation recovered their body weight more quickly than those not receiving RG extract supplementation. We propose that the dietary intake of RG extract and RG saponin enhances the vaccine-induced immune response and aids in providing protection against influenza virus infection.
\end{abstract}

Keywords: Panax ginseng, Korean red ginseng, Influenza A virus, Saponin

\section{INTRODUCTION}

Ginseng (Panax ginseng) is a traditional medicine, and it has been widely used for more than 2,000 years in China, Korea, and Japan. Ginseng is also one of the most widely used herbs in the United State: a national survey of men and women in the United States found that $4 \%$ to $5 \%$ of those aged 45 to 64 yr used ginseng [1]. Ginseng contains saponin, essential oils, antioxidants, polyacetylenic alcohol, peptides, vitamins, and polysaccharides [2] and it is known to have a wide range of therapeutic and pharmacological activities [3,4]. Moreover, many reports have suggested that ginseng acts as an anti-inflammatory, anti-cancer, anti-viral, and antiaging agent $[2,5,6]$.
More than 40 different saponins have been isolated and identified from the root of ginseng [7]. The ginseng root contains $2 \%$ to $3 \%$ saponins, of which $\mathrm{Rg} 1, \mathrm{Rc}, \mathrm{Rd}$, $\mathrm{Re}, \mathrm{Rb} 1, \mathrm{Rb} 2$, and $\mathrm{Rb} 0$ are considered to be the most important [5]. Accumulating data indicate that saponins are responsible for ginseng functionality [5] and researchers have investigated a potential adjuvant effect of ginseng extract and ginseng saponin [8]. It has been suggested that ginseng extract and ginseng saponin increase humoral and cellular immune responses when used as an adjuvant for vaccination [8-10]. However, their use as a vaccine adjuvant has been limited due to associated toxicity [11]. (c) This is an Open Access article distributed under the terms of the Creative Commons Attribution Non-Commercial License (http://creativecommons.org/licenses/by-nc/3.0/) which permits unrestricted non-commercial use, distribution, and reproduction in any medium, provided the original work is properly cited.
Received 16 Jul. 2012, Revised 25 Jul. 2012, Accepted 25 Jul. 2012

*Corresponding author

E-mail: hongjink@cau.ac.kr

Tel: +82-2-820-5613, Fax: +82-2-816-7338 
Influenza virus is one of the most common causes of serious respiratory illness [12]. The epidemic caused by influenza virus results in 3 to 5 million patients with severe cases and 0.25 to 0.5 million deaths each year [13]. Vaccination is the main strategy for preventing and controlling seasonal influenza and is a key strategy in preparing for pandemic influenza outbreaks [14]. It is thought that vaccine efficacy may be influenced by several factors including age, health status, and the use of concurrent medications [15]. The Centers for Disease Control and Prevention estimates that the clinical vaccine efficacy is $70 \%$ to $90 \%$ in young adults [16]. However, vaccine efficacy in those over $65 \mathrm{yr}$ of age is $17 \%$ to $53 \%$ [17]. Indeed, the elderly over $65 \mathrm{yr}$ of age currently account for approximately $90 \%$ of all influenza-related deaths [18] and the weak anti-influenza virus antibody response in the elderly is thought to be a cause of the low vaccine efficacy [17]. Therefore, considerable effort has been made toward enhancing the vaccine-induced antibody response in the elderly [19]. In addition, vaccine efficacy in individuals with high-risk medical conditions may be much lower compared with those without high-risk medical conditions [20]. Therefore, increasing vaccine efficacy is a high priority in the field of influenza vaccine design.

Many studies indicate that ginseng extract and ginseng saponin can modulate or enhance the immune response $[8,21]$. However, there has been little examination of how dietary intake of ginseng extract or ginseng saponin affects vaccine-induced immune response and protection. In this study, we investigated the effect of dietary Korean red ginseng $(\mathrm{RG})$ extract and $R G$ saponin on immunization with inactivated influenza $A$ virus.

\section{MATERIALS AND METHODS}

\section{Materials}

RG extract was obtained from Geumsan Korean Ginseng Nonghyup (Geumsan, Korea). RG saponin was obtained from the Ambo Institute (Daejeon, Korea). RG extract and RG saponin were dissolved in distilled water at a concentration of $0.025 \mathrm{mg} / \mathrm{mL}$ (the concentrations were based on the residual amounts of RG extract and RG saponin).

\section{Preparation of virus}

Influenza A/PR/8/34 virus (H1N1 subtype) was kindly donated by Professor Baik Lin Seong (Yonsei University, Seoul, Korea). Influenza A virus was propagated in 11-day-old fertilized chicken eggs at $37^{\circ} \mathrm{C}$ for $48 \mathrm{~h}$. Egg allantoic fluid was clarified by centrifugation at $682 \mathrm{~g}$ for
$10 \mathrm{~min}$ and filtered using a $0.22 \mu \mathrm{m}$ syringe filter. The $50 \%$ lethal dose $\left(\mathrm{LD}_{50}\right)$ of the influenza A stock was determined as previously described [22].

\section{Preparation of inactivated whole virus vaccine}

The influenza A virus was dialyzed against binding buffer for anion-exchange chromatography $(20 \mathrm{mM}$ $\mathrm{Na}_{2} \mathrm{HPO}_{4}, 150 \mathrm{mM} \mathrm{NaCl} \mathrm{pH} 7.3$ ) at $4{ }^{\circ} \mathrm{C}$ for $4 \mathrm{~h}$. The dialyzed virus was clarified by centrifugation at 12,000 $\times \mathrm{g}$ for $10 \mathrm{~min}$ and loaded on an anion-exchange column (Q sepharose FF; GE Healthcare, Piscataway, NJ, USA), which was equilibrated with the binding buffer. The influenza A virus bound by the anion-exchange resin was eluted with a linear gradient of $\mathrm{NaCl}$, from 0.15 to $1.5 \mathrm{M}$, and concentrated using the Amicon Ultra centrifugal filter (Millipore, Billercia, MA, USA). The concentrated virus was further purified by size-exclusion chromatography $(2.8 \times 30 \mathrm{~cm}$ of Superose- 6 resin, GE Healthcare). The hemagglutination activity (HA) of purified influenza A virus was confirmed using chicken erythrocyte cells as an indicator [23]. The purified virus was diluted with phosphate-buffered saline (PBS) to prepare the vaccine formulation, which consisted of $40 \mu \mathrm{L}$ of PBS containing $\log 2^{4} \mathrm{HA}$ titer of influenza A virus. The formulation was inactivated with $0.02 \%$ formalin at $4^{\circ} \mathrm{C}$ for $72 \mathrm{~h}[24]$.

\section{Sodium dodecyl sulfate-polyacrylamide gel elec- trophoresis and Western blot}

Sodium dodecyl sulfate-polyacrylamide gel electrophoresis (SDS-PAGE) was performed according to the method of Laemmli [25]. Separated proteins were visualized using a silver staining kit (GE Healthcare). To detect proteins of influenza A virus via Western blot, mouse anti-influenza A virus polyclonal antibody and horseradish peroxidase (HRP)-conjugated anti-mouse IgG antibody (Bethyl, Montgomery, TX, USA) were used. The antiinfluenza A virus polyclonal antibody was obtained from mice infected two times with influenza A (H1N1) virus.

\section{Animals}

Five-week-old female Balb/c mice were purchased from Orient Bio (Seongnam, Korea) and acclimatized for $1 \mathrm{wk}$. All animal experiments were performed in accordance with the National Research Council's Guide for the Care and Use of Laboratory Animals and with the Guidelines for Animal Experiments of Chung-Ang University and they were approved by the university committee for animal experiments. 


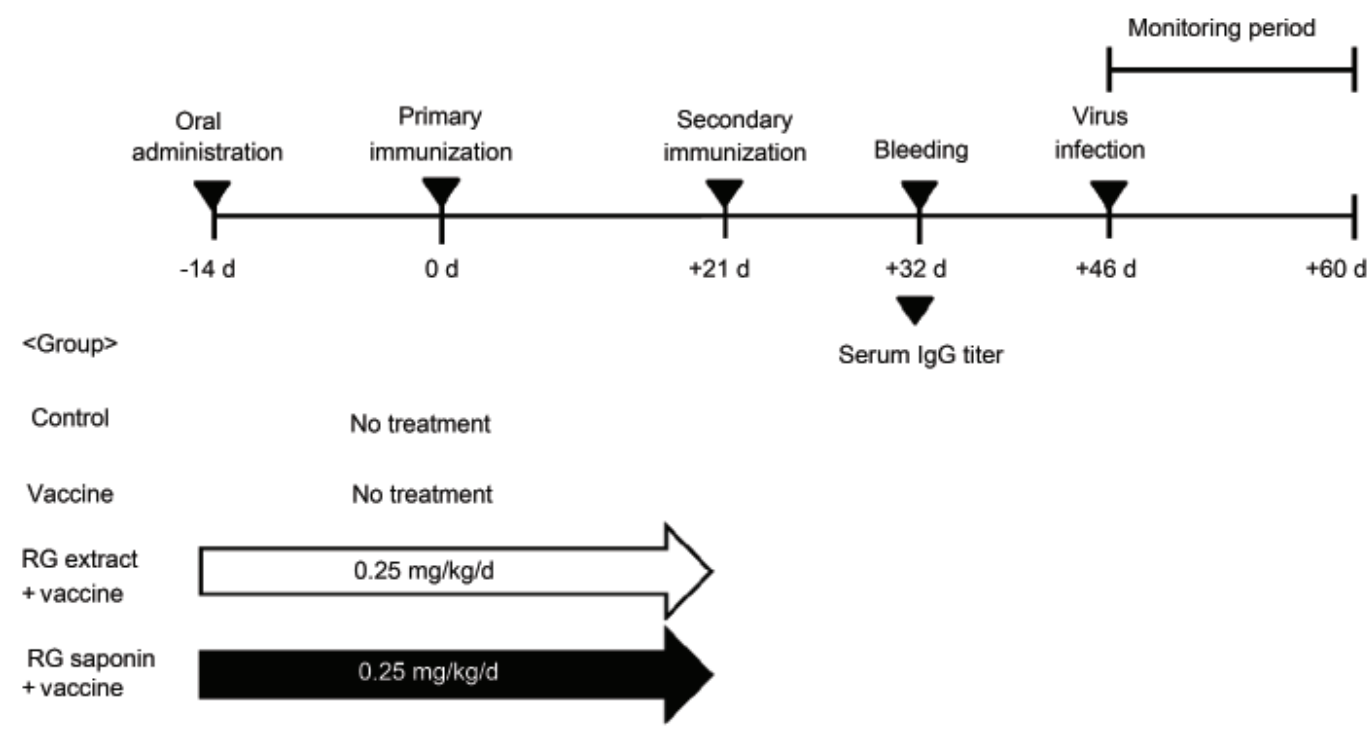

Fig. 1. Diagram of the animal experiments. The control and vaccine groups were not given any supplements except water and feed during immunization. The red ginseng (RG) extract + vaccine and RG saponin + vaccine groups were given RG extract and RG saponin, respectively, for $14 \mathrm{~d}$ prior to primary immunization. These two mouse groups were then given RG extract and RG saponin for $21 \mathrm{~d}$ until the secondary immunization. Eleven days after the secondary immunization, blood was collected from mouse tails and was assayed for anti-influenza virus IgG. Fourteen days after blood collection, mice were challenged with $10 \mathrm{LD}_{50}$ of influenza A virus. Survival and body weight were monitored for $14 \mathrm{~d}$.

\section{Administration of RG extract and RG saponin and immunizations with inactivated virus}

Mice were divided into four groups (control, vaccine, $\mathrm{RG}$ extract + vaccine, and RG saponin + vaccine), each consisting of sixteen mice. The dosing schedule and immunization schedule for each group are shown in Fig. 1. Prior to the immunization, both the control and vaccine groups did not received any material aside from arbitrarily ingested water and feed, while the RG extract + vaccine and RG saponin + vaccine groups received $R G$ extract $(0.25 \mathrm{mg} / \mathrm{kg} / \mathrm{d})$ or $\mathrm{RG}$ saponin $(0.25 \mathrm{mg} / \mathrm{kg} /$ d) orally for $14 \mathrm{~d}$, respectively. After the oral administrations, vaccine, the RG extract + vaccine, and RG saponin + vaccine groups were immunized intranasally two times with the inactivated whole virus vaccine $(40 \mu \mathrm{L}$ of PBS containing $\log 2^{4} \mathrm{HA}$ titer of purified influenza A virus) at a three week interval. The control group remained unvaccinated. After the primary immunization, the RG extract + vaccine and RG saponin + vaccine groups continued to receive $R G$ extract $(0.25 \mathrm{mg} / \mathrm{kg} / \mathrm{d})$ or $R G$ saponin $(0.25 \mathrm{mg} / \mathrm{kg} / \mathrm{d})$ orally until the secondary immunization. Eleven days after the secondary immunization, mice sera were collected and assayed.

\section{Virus challenge against mice immunized with in- activated influenza $A$ virus}

Twenty-five days after the secondary immunization, the mice were challenged intranasally with $10 \mathrm{LD}_{50}$ of influenza A virus. Body weights and survival were monitored for $14 \mathrm{~d}$. The body weight of each mouse one day before virus challenge was defined as $100 \%$.

\section{Titration of anti-influenza A virus IgG}

The titers of anti-influenza A virus IgG were determined as described previously, with slight modifications [26]. Briefly, 96-well enzyme-linked immunosorbent assay plates (Greiner Bio One, Frickenhausen, Germany) were coated overnight at $4^{\circ} \mathrm{C}$ with $500 \mathrm{ng}$ per well of whole influenza $\mathrm{A}$ virus and they were then blocked with $5 \%$ skim milk (Bioworld, Atlanta, GA, USA) in PBS containing $0.05 \%$ Tween 20 at room temperature for $2 \mathrm{~h}$. The plate was incubated with serially diluted mice sera at $37^{\circ} \mathrm{C}$ for $1 \mathrm{~h} 30 \mathrm{~min}$. The anti-influenza A IgG bound to the influenza A virus were detected by incubation $\left(37^{\circ} \mathrm{C}\right.$ for $\left.1 \mathrm{~h}\right)$ with HRP-conjugated goat anti-mouse IgG antibody (Bethyl). The reaction was developed with o-phenylenediamine (Sigma, St. Louis, MO, USA) as the substrate and was read at $492 \mathrm{~nm}$. End-point titers were defined as an optical density of 1.5 times the control wells, in which sera of mice from the normal group were applied. Data are presented as mean \pm standard error of mean.

\section{Statistical analysis}

The statistical significance of differences between groups was determined using a two-tailed Student's $t$ - 
A

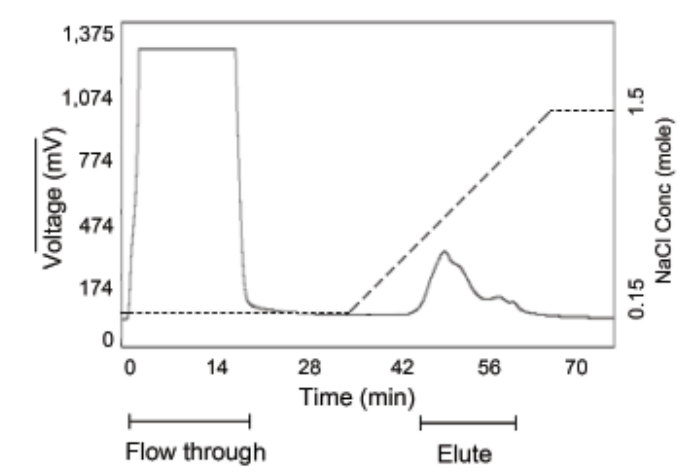

B

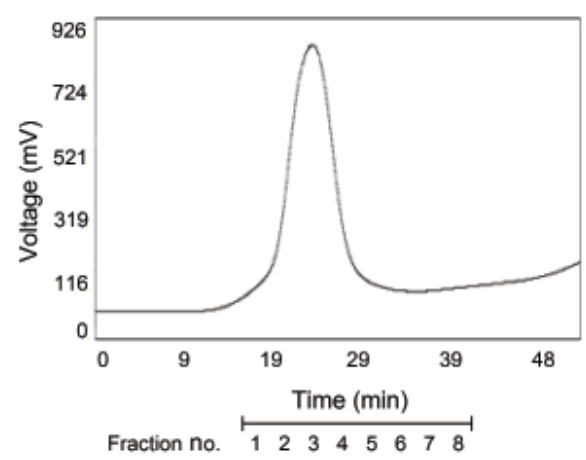

C
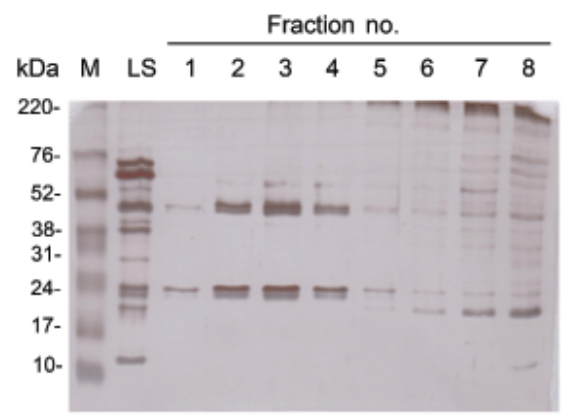

D

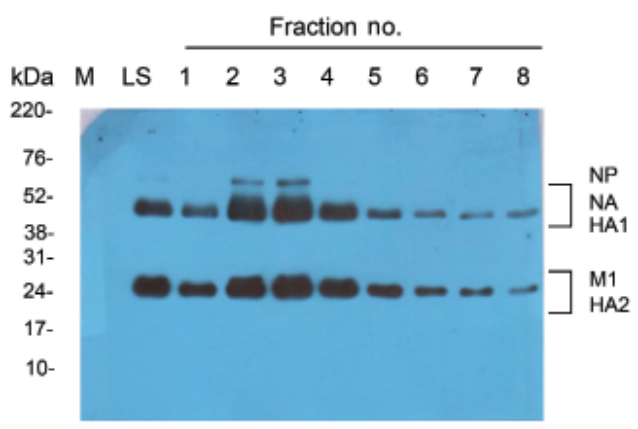

Fig. 2. Purification of influenza A virus. The influenza A virus was propagated in chicken eggs and harvested as described in Materials and Methods. The virus was purified by anion-exchange chromatography and subsequently by size-exclusion chromatography. (A) and (B) are chromatography profiles of anion exchange and size-exclusion chromatography, respectively. The elution profiles were acquired with Autochro-2000 software (Young Lin Instrument Co., Anyang, Korea). The virus was eluted with a linear gradient of $\mathrm{NaCl}$ from 0.15 to $1.5 \mathrm{M}$. The virus elute was further separated by size-exclusion chromatography. Fractions 1 to 8 of the size-exclusion chromatography were analyzed by sodium dodecyl sulfate-polyacrylamide gel electrophoresis (C) and Western blot (D). LS refers to sample loaded for size-exclusion chromatography. Conc, concentration; M, marker; NP, nucleoprotein; NA, neuraminidase; HA1, hemagglutinin 1; M1, matrix protein; HA2, hemagglutinin 2 of influenza virus.

test. A $p$-value less than 0.05 was considered statistically significant.

\section{RESULTS}

\section{Preparation of the inactivated whole virus vaccine}

Influenza A virus was harvested from chicken egg allantoic fluid and sequentially purified by anion-exchange and size-exclusion chromatography. The influenza A virus was successfully eluted with a linear gradient of $\mathrm{NaCl}$ using anion-exchange chromatography (Fig. 2A). The eluted fraction was further separated by size-exclusion chromatography (Fig. 2B). As shown in Fig. 2C, the influenza A virus fractionated from size-exclusion chromatography was confirmed to have proteins ranging from 23 to 25 and 50 to $60 \mathrm{kDa}$ on SDS-PAGE and these proteins were also detected by Western blot (Fig. 2D), indicating that the purity of influenza virus was high. The protein composition of purified influenza A virus was similar to that of a previous report [27]. The fractions from 2 to 4 were collected, inactivated and used for immunization.

\section{Humoral immune response following vaccination}

Eleven days after the second immunization, mice sera were obtained, and the anti-influenza A virus IgG titers were measured. The mean IgG titers of the $\mathrm{RG}$ extract + vaccine and $R G$ saponin + vaccine groups were 3,468 and 2,109, respectively, while that of the vaccine group was 1,071 (Fig 3). Therefore, dietary intake of RG extract and RG saponin were confirmed to enhance the humoral immune response induced by vaccination with inactivated influenza A virus.

\section{Comparison of the survival and change in body weight of mice vaccinated following virus chal- lenge}

Each mouse group was challenged with $10 \mathrm{LD}_{50}$ influenza A virus following the two immunizations. Fiftysix percent of the mice in the RG extract + vaccine group and $63 \%$ of the mice in the RG saponin + vaccine 


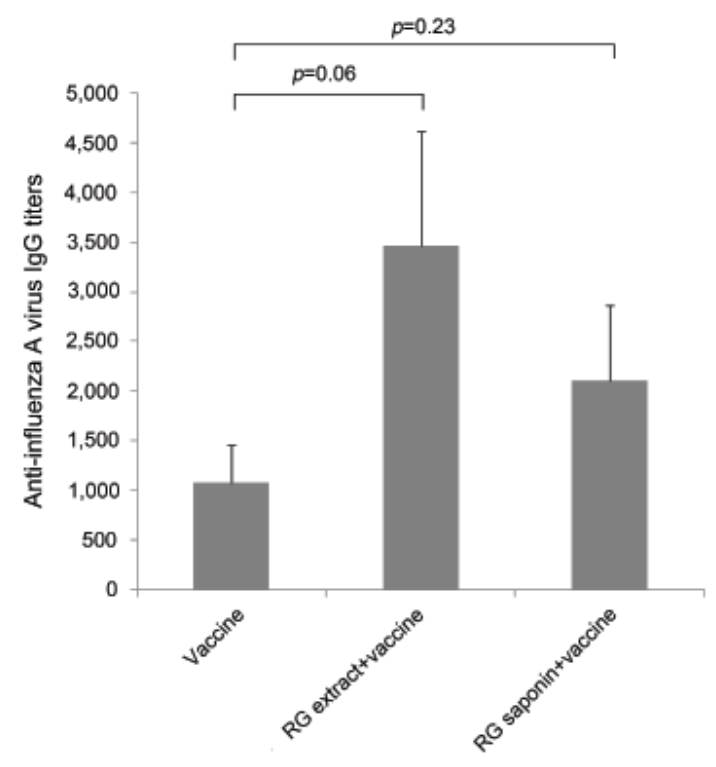

Fig. 3. Anti-influenza A virus IgG titers following vaccination. Mice were immunized two times intranasally with the inactivated whole virus vaccine. Eleven days after the second immunization mice sera were collected and assayed. Anti-influenza A virus IgG titers were determined as described in Materials and Methods. Data are mean \pm standard error of mean of sixteen mice $(n=16)$. RG, red ginseng.

groups survived, while only $38 \%$ of mice in the vaccine group survived (Fig. 4A). Additionally, the mice in the $\mathrm{RG}$ extract + vaccine group recovered their body weight more quickly than those in the RG saponin + vaccine or vaccine groups (Fig. 4B). Therefore, it was confirmed that the vaccinations, in combination with oral supplementation with RG extract or RG saponin, increased the protection against lethal influenza A virus infection. Moreover, vaccination combined with oral supplementation with RG extract appeared to promote the recovery of body weight after influenza infection.

\section{DISCUSSION}

RG extract and RG saponin have been shown to elevate antigen-specific immune response when they are coinjected with antigen [28]. Saponins are a heterogeneous group of sterols and triterpene glycosides and have been isolated from a broad range of plants [11,29]. The saponins induce both the apoptosis and necrosis of immune cells, and the cell death signals are thought to contribute to their adjuvant effects [30]. The cytotoxicity of saponins has hindered their use as an adjuvant in humans, although their adjuvant effects are of value [11]. Many studies have utilized intraperitoneal and intramuscular injections to investigate the adjuvant effect of ginseng extract and saponins [21,31]. In this study, we focused on the effects of
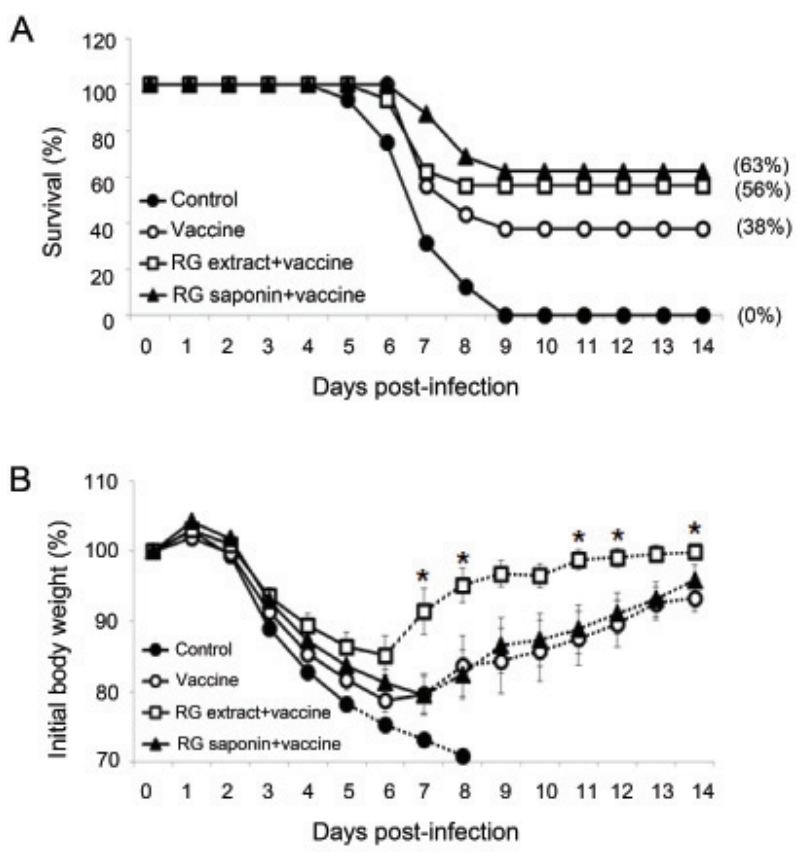

Fig. 4. The survival and change in body weight of mice following infection with a $10 L D_{50}$ of influenza $A$ virus. Mice immunized two times with inactivated influenza $A$ virus were challenged intranasally with $10 L_{50}$ of influenza $A$ virus. Survival $(A)$ and changes in body weight (B) were monitored for $14 \mathrm{~d}$. Body weight at $1 \mathrm{~d}$ prior to virus challenge was defined as $100 \%$. In (B), the percentage of body weight is presented as the mean \pm standard error of mean of sixteen mice $(n=16)$. The dotted line represents the mean body weight of mice that survived. ${ }^{*} p<0.05$ indicates a difference in body weight between the control and red ginseng (RG) extract + vaccine group.

RG extract and RG saponin when they are administered via the oral route during nasal vaccination. Our experimental design corresponds to the traditional use of RGs, which is ingestion through the oral route, rather than the more recent focus on RGs for adjuvant use.

Anti-influenza IgG contributes to vaccine-induced protective immunity and is thought to significantly correlate with mouse survival in the lethal influenza infection model $[32,33]$. In this study, vaccination in combination with oral administration of RG extract and RG saponin enhanced the anti-influenza virus IgG titer (Fig. 3) and protection against lethal influenza virus infection (Fig. 4). Therefore, the higher levels of anti-influenza virus IgG induced by supplementation with RGs are thought to contribute to the higher mouse survival rate. Interestingly, vaccination with oral supplementation of RG extract significantly promoted the recovery of body weight, while supplementation with RG saponin did not (Fig. 4B). This result indicates that the function of RG extract in the vaccine-induced immune response is different from that of RG saponin. Previous reports indicated that the influenza-specific $\mathrm{CD} 8^{+}$cytotoxic $\mathrm{T}$ cells play a piv- 
otal role in clearing virus and promoting recovery from influenza disease [34]. In addition, alternatively activated macrophages (AAM) are thought to be associated with the maintenance of tissue homeostasis or to be involved with tissue remodeling, wound healing, and the dampening of inflammatory responses [35,36]. It has been proposed that the AAM may also promote tissue repair and healing during recovery from influenza infection [37]. Therefore, we assume that components of the RG extract other than saponin may increase cell-mediated immunity associated with tissue repair and healing during vaccination.

In conclusion, our results suggest that dietary intake of RG extract and RG saponin enhances the protection afforded mice upon vaccination against influenza virus. Our strategy for enhancing vaccine efficacy is simple and safe, and there is little risk of side effects. We anticipate that further investigation of the effect of RG components when used with vaccination for humans will provide suitable prescriptions for the elderly and patients at a high risk for influenza infection.

\section{ACKNOWLEDGEMENTS}

We thank Professor Man-Seong Park (Hallym University, Chuncheon, Korea) and Professor Baik-Lin Seong (Younsei University, Seoul, Korea) for help with the experiments. This research was supported by the ChungAng University Research Scholarship Grants in 2011.

\section{REFERENCES}

1. Kaufman DW, Kelly JP, Rosenberg L, Anderson TE, Mitchell AA. Recent patterns of medication use in the ambulatory adult population of the United States: the Slone survey. JAMA 2002;287:337-344.

2. Wee JJ, Park MK, Chung AS. Biological activities of ginseng and its application to human health. In: Benzie IF, Wachtel-Galor S, eds. Herbal medicine: biomolecular and clinical aspects. 2nd ed. Boca Raton: CRC Press, 2011. p. 157-174.

3. Kim SK, Park JH. Trends in ginseng research in 2010. J Ginseng Res 2011;35:389-398.

4. Ernst E. Panax ginseng: An overview of the clinical evidence. J Ginseng Res 2010;34:259-263.

5. Lu JM, Yao Q, Chen C. Ginseng compounds: an update on their molecular mechanisms and medical applications. Curr Vasc Pharmacol 2009;7:293-302.

6. Kim JY, Kim HY, Kim HJ. Effect of oral administration of Korean red ginseng on influenza A (H1N1) virus infection. J Ginseng Res 2011;35:104-110.
7. Nah SY. Ginseng: recent advances and trends. Korean J Ginseng Sci 1997;21:1-12.

8. Sun HX, Xie Y, Ye YP. Advances in saponin-based adjuvants. Vaccine 2009;27:1787-1796.

9. Jie YH, Cammisuli S, Baggiolini M. Immunomodulatory effects of Panax ginseng C.A. Meyer in the mouse. Agents Actions 1984;15:386-391.

10. Rivera E, Daggfeldt A, Hu S. Ginseng extract in aluminium hydroxide adjuvanted vaccines improves the antibody response of pigs to porcine parvovirus and Erysipelothrix rhusiopathiae. Vet Immunol Immunopathol 2003;91:1927.

11. Skene CD, Sutton P. Saponin-adjuvanted particulate vaccines for clinical use. Methods 2006;40:53-59.

12. Roxas M, Jurenka J. Colds and influenza: a review of diagnosis and conventional, botanical, and nutritional considerations. Altern Med Rev 2007;12:25-48.

13. World Health Organization. Influenza (seasonal): fact sheet no. 211. Available from: http://www.who.int/mediacentre/factsheets/fs211/en/index.html.

14. Nichol KL. Improving influenza vaccination rates among adults. Cleve Clin J Med 2006;73:1009-1015.

15. Hannoun C, Megas F, Piercy J. Immunogenicity and protective efficacy of influenza vaccination. Virus Res 2004;103:133-138.

16. Centers for Disease Control and Prevention. Flu vaccine effectiveness: questions and answers for health professionals. Available from: http://www.cdc.gov/flu/professionals/vaccination/effectivenessqa.htm.

17. Goodwin K, Viboud C, Simonsen L. Antibody response to influenza vaccination in the elderly: a quantitative review. Vaccine 2006;24:1159-1169.

18. Centers for Disease Control and Prevention (CDC). Estimates of deaths associated with seasonal influenza: United States, 1976-2007. MMWR Morb Mortal Wkly Rep 2010;59:1057-1062.

19. Foster SL, Moore WP. High-dose influenza vaccination in the elderly. J Am Pharm Assoc (2003) 2010;50:546-547.

20. Herrera GA, Iwane MK, Cortese M, Brown C, Gershman K, Shupe A, Averhoff F, Chaves SS, Gargiullo P, Bridges $\mathrm{CB}$. Influenza vaccine effectiveness among 50-64-yearold persons during a season of poor antigenic match between vaccine and circulating influenza virus strains: Colorado, United States, 2003-2004. Vaccine 2007;25:154160.

21. Hu S, Concha C, Lin F, Persson Waller K. Adjuvant effect of ginseng extracts on the immune responses to immunisation against Staphylococcus aureus in dairy cattle. Vet Immunol Immunopathol 2003;91:29-37.

22. Reed LJ, Muench H. A simple method of estimating fifty 
percent endpoints. Am J Hyg 1938;27:493-497.

23. Xu L, Bao L, Lv Q, Deng W, Ma Y, Li F, Zhan L, Zhu H, Ma C, Qin C. A single-amino-acid substitution in the HA protein changes the replication and pathogenicity of the 2009 pandemic A (H1N1) influenza viruses in vitro and in vivo. Virol J 2010;7:325.

24. Prabakaran M, Velumani S, He F, Karuppannan AK, Geng GY, Yin LK, Kwang J. Protective immunity against influenza $\mathrm{H} 5 \mathrm{~N} 1$ virus challenge in mice by intranasal coadministration of baculovirus surface-displayed HA and recombinant CTB as an adjuvant. Virology 2008;380:412420.

25. Laemmli UK. Cleavage of structural proteins during the assembly of the head of bacteriophage T4. Nature 1970;227:680-685.

26. Prabakaran M, Madhan S, Prabhu N, Geng GY, New R, Kwang J. Reverse micelle-encapsulated recombinant baculovirus as an oral vaccine against $\mathrm{H} 5 \mathrm{~N} 1$ infection in mice. Antiviral Res 2010;86:180-187.

27. Shaw ML, Stone KL, Colangelo CM, Gulcicek EE, Palese P. Cellular proteins in influenza virus particles. PLoS Pathog 2008;4:e1000085.

28. Song X, Hu S. Adjuvant activities of saponins from traditional Chinese medicinal herbs. Vaccine 2009;27:48834890.

29. Morein B, Sundquist B, Hoglund S, Dalsgaard K, Osterhaus A. Iscom, a novel structure for antigenic presentation of membrane proteins from enveloped viruses. Nature 1984;308:457-460.
30. Wu CA, Yang YW. Induction of cell death by saponin and antigen delivery. Pharm Res 2004;21:271-277.

31. Rajput ZI, Hu SH, Xiao CW, Arijo AG. Adjuvant effects of saponins on animal immune responses. J Zhejiang Univ Sci B 2007;8:153-161.

32. Huber VC, McKeon RM, Brackin MN, Miller LA, Keating R, Brown SA, Makarova N, Perez DR, Macdonald $\mathrm{GH}$, McCullers JA. Distinct contributions of vaccineinduced immunoglobulin G1 (IgG1) and IgG2a antibodies to protective immunity against influenza. Clin Vaccine Immunol 2006;13:981-990.

33. Yasui H, Kiyoshima J, Hori T, Shida K. Protection against influenza virus infection of mice fed Bifidobacterium breve YIT4064. Clin Diagn Lab Immunol 1999;6:186192.

34. Mbawuike IN, Zhang Y, Couch RB. Control of mucosal virus infection by influenza nucleoprotein-specific CD8+ cytotoxic T lymphocytes. Respir Res 2007;8:44.

35. Mosser DM, Edwards JP. Exploring the full spectrum of macrophage activation. Nat Rev Immunol 2008;8:958969.

36. Gordon S. Alternative activation of macrophages. Nat Rev Immunol 2003;3:23-35.

37. Chen WH, Toapanta FR, Shirey KA, Zhang L, Giannelou A, Page C, Frieman MB, Vogel SN, Cross AS. Potential role for alternatively activated macrophages in the secondary bacterial infection during recovery from influenza. Immunol Lett 2012;141:227-234. 